\title{
Detection of Aeromonas salmonicida in Atlantic salmon with asymptomatic furunculosis infections
}

\author{
M. P. Hiney, J. J. Kilmartin, P. R. Smith \\ Fish Disease Group, Department of Microbiology, University College Galway, Galway, Ireland
}

\begin{abstract}
Standard bacteriology and enzyme-linked immunosorbent assay (ELISA) were employed to detect Aeromonas salmonicida in samples of kidney, intestine and mucus from pre-smolt Atlantic salmon Salmo salar with stress-inducible furunculosis infections. No A. salmonicida was isolated by bacteriological culture of samples from 30 unstressed salmon. In the same samples, ELISA detected antigen in 15 intestinal samples, but none in any of the kidney or mucus samples. The frequency of stress-inducible infections in a paired group of Atlantic salmon was 7/29 when the kidneys of the stressed fish were examined bacteriologically and 13/29 when ELISA results from kidney, intestinal content and mucus were combined. If ELISA results from kidneys alone were considered the frequency of detection was $8 / 20$. In 2 separate experiments brown trout enrichment was used to detect $A$. salmonicida in pre-smolt Atlantic salmon with stress-inducible infections and compared to the standard stress test. The pathogen was detected in the combined mucus, fins and gills of $7 / 20$ and $14 / 20$ fish and in the blood of $3 / 20$ and $2 / 20$ fish respectively. The frequency of stress-inducible infections in paired groups of fish from the same populations was $10 / 20$ and $16 / 20$ respectively. These data suggest that the intestine may be the primary location of $A$. salmonicida in salmon with stress-inducible infections and that colonisation of the mucus, fins and gills may also occur. The implications of these findings for the design of methods to eliminate such infections are discussed.
\end{abstract}

KEY WORDS: Aeromonas salmonicida $\cdot$ Detection $\cdot$ Asymptomatic infection - Intestine $\cdot$ Mucus

\section{INTRODUCTION}

The importance of asymptomatic infections has been recognised by the majority of those who have studied the epizootiology of furunculosis (Plehn 1911, Mettam 1914, Horne 1928, Mackie \& Menzies 1938, Klontz 1968, Bullock \& Stuckey 1975, McCarthy 1977). Hastings (1988) and Smith (1992) have argued that such infections play an important role in the transmission of the disease in commercial salmon farming. The literature on asymptomatic infections is, however, complicated by the variety of methods that have been used to detect such infections. Early workers (Plehn 1911, Mettam 1914, Horne 1928) detected asymptomatic infections by holding fish for a period of months and waiting for overt disease to develop, or by determining the ability of asymptomatically infected fish to transmit overt infection to healthy fish during cohabitation. Mackie \& Menzies (1938) recommended bacteriological examination of the kidney for the identification of fish with such infections. McDermott \& Berst (1968) and Daly \& Stevenson (1985) reported that reliance on bacteriological examination of the kidney alone was inefficient and that a variety of organs should be examined. This conclusion was supported by Rose et al. (1989) who used an enzyme-linked immunosorbent assay (ELISA) technique to detect infections in unstressed fish. Klontz (1968) suggested that the primary site of carriage was the intestine and reported the detection of asymptomatic infections by fluorescent antibody examination of intestinal swabs. Cipriano et al. (1992) deduced the asymptomatic infection status of fish populations from their previous clinical histories and suggested that bacterial culture of the mucus was of value.

The hormone and heat stress test introduced by Bullock \& Stuckey (1975) and modified by McCarthy (1977) has provided a method which detects higher frequencies of asymptomatic Aeromonas salmonicida 
infections than bacteriological methods (Bullock \& Stuckey 1975, Scallan 1983). The epizootiological relevance of this test has been demonstrated by its application to the control of smolt transfers by commercial salmon farmers. This has resulted in effective control of the spread of furunculosis from fresh water hatcheries to uninfected sea farms (Smith 1992). The major limitation of the stress test is the length of time required to perform the test and the large number of fish that have to be sacrificed to generate a statistically significant result.

Different methods of detection of asymptomatic infections yield different frequencies of infection (Bullock \& Stuckey 1975, Scallan 1983, Rose et al. 1989). It is possible that the methods, in fact, detect different types of infection. Given this lack of a standard ex perimental definition, it is difficult to compare the observations of various investigators with respect to the suggested location of the pathogen.

McCarthy (1977) suggested that the most probable location of the pathogen in asymptomatically infected fish was the kidney and this is supported by the results of Rose et al. (1989). Using ELISA they presented evidence that the pathogen could most frequently be isolated from the kidney of asymptomatically infected fish and that intestinal samples were less frequently positive. Markwardt \& Klontz (1989a), on the other hand, have developed a method of experimentally inducing asymptomatic infection with Aeromonas salmonicida which assumes that the intestine is the only significant location of the pathogen in such infections. Cipriano et al. (1992) have recently suggested that the external mucus may also harbour the pathogen in asymptomatically infected fish

The aim of this work was 2 -fold. It was undertaken to obtain a quantitative comparison of the efficiency of ELISA and a novel method (the 'brown trout enrichment' method) with the epizootiologically validated stress test in detecting asymptomatic infections. The second aim was to investigate the location of the pathogen in asymptomatically infected fish in the light of the suggestions of Klontz (1968) and Cipriano et al. (1992).

\section{MATERIALS AND METHODS}

Fish holding facilities. Prior to the start of any experiments, all fish were held in $500 \mathrm{l}$ aerated tanks, at a stocking density of 3.0 to $3.6 \mathrm{~kg} \mathrm{~m}^{-3}$ and at ambient temperature, for $3 \mathrm{~d}$ following transport to our fish holding facilities. This facility was supplied with carbon filtered, chlorinated water. No mortalities occurred in either salmon or brown trout populations during their initial $3 \mathrm{~d}$ holding periods.
Salmon. Pre-smolt Atlantic salmon Salmo salar L. used in all experiments in this study were obtained from a commercial hatchery with a documented history of furunculosis (Scallan 1983). Fish weight was 20 to $30 \mathrm{~g}$. The hatchery population was free from clinical furunculosis during the experimental periods.

Brown trout. Brown trout Salmo trutta L. (weight range 20 to $30 \mathrm{~g}$ ) were obtained from a hatchery with a furunculosis-free history. A sub-sample $(n=20)$ was tested for stress-inducible furunculosis (SIF) by a modified stress test prior to each experiment.

Modified stress test. For the purpose of these experiments a modification of the stress test of McCarthy (1977) was used as described by Scallan \& Smith (1084). Twenty to thirty fish were held individually in $4 \mathrm{l}$ tanks (stocking density of 5 to $6 \mathrm{~kg} \mathrm{~m}^{-3}$ ) for $14 \mathrm{~d}$ at $18^{\circ} \mathrm{C}$ following intramuscular (i.m.) injection with prednisolone acetate. The kidneys of mortalities incurred during the test and survivors of the test were bacteriologically analysed for the presence of Aeromonas salmonicida on tryptone soya agar (TSA) and brain heart infusion agar (BHIA) supplied by Oxoid, England. These plates were incubated at $22^{\circ} \mathrm{C}$ for $72 \mathrm{~h}$ and any putative $A$. salmonicida colonies were examined by the method of Drinan (1985).

Comparison of ELISA, bacteriology and stress test. Sixty pre-smolt salmon were removed from their holding tank and divided into 2 groups of 30 fish. The first group (A) was subjected to stress testing, while the second group (B) was sacrificed by overdosing with benzocaine (Sigma). Samples of the mucus layer, intestinal contents and kidney were taken from each individual salmon in group B. Mucus was obtained by gently passing a sterile scalpel along the operculum and lateral body surface of individual fish. Each salmon was then necropsied: the abdomen was opened using a sterile scalpel and the intestine was severed as close as possible to the anal region of the salmon. Using a sterile forceps the intestinal contents were gradually squeezed along the length of the posterior intestine and out at the severed end into a sterile plastic bottle. A portion of the kidney was also removed aseptically.

These samples were divided into two. One half of each sample was streaked directly onto TSA and BHIA, incubated at $22^{\circ} \mathrm{C}$ for $72 \mathrm{~h}$ and any putative Aeromonas salmonicida colonies were examined by the method of Drinan (1985). The second half of each individual sample $(0.4$ to $0.5 \mathrm{~g})$ was placed in $10 \mathrm{ml}$ of antigen extraction buffer and analysed by ELISA according to the manufacturer's instructions, using a commercial kit specific for $A$. salmonicida (Stirling Diagnostics Ltd., Stirling, Scotland). This kit consists of 
sheep anti-A. salmonicida whole cell antibody as the capture reagent and sheep anti- $A$. salmonicida whole cell antibody conjugated to horseradish peroxidase as the detection reagent. The kit is designed to detect A. salmonicida in extracted kidney material. Optical density measurements of all samples were made on a Dynatech MR5000 plate reader. In all tests the negative control values were within the limits stipulated by the manufacturers. The lower limit of detection was $1 \times 10^{4}$ colony-forming units ( $\mathrm{cfu}$ ) $\mathrm{ml}^{-1}$, equivalent to an optical density of 0.09 OD units. Thus, only samples giving an $O D$ reading above this value were considered to be positive.

Comparison of brown trout enrichment, bacteriology and stress test. On 2 separate occasions 40 presmolt salmon, which had been acclimatised for $2 \mathrm{~d}$ following transport from the hatchery, were removed from their holding tank and divided into 2 groups of 20 fish. The first group (C) was stress tested, while the second group (D) was sampled as follows. Blood (1 ml) was drawn from the caudal vessel and samples of mucus, fins and gills were removed aseptically from each salmon. In addition, a loopful of kidney was obtained aseptically from each group $D$ salmon for bacteriological examination

Samples of mucus, fins, and gills from individual salmon were combined in sterile containers with $10 \mathrm{ml}$ of sterile phosphate-buffered saline (PBS) (Oxoid). Following thorough mixing on a vortex for $1 \mathrm{~min}$, the supernatant was transferred to $15 \mathrm{ml}$ centrifuge tubes and spun at $5000 \mathrm{rpm}$ for $15 \mathrm{~min}$. The resulting pellet was re-suspended in $1 \mathrm{ml}$ of PBS. A loopful of each suspended pellet and of kidney were streaked onto TSA and BHIA, incubated at $22^{\circ} \mathrm{C}$ for $72 \mathrm{~h}$, and any putative Aeromonas salmonicida colonies were examined by the method of Drinan (1985).

In preliminary experiments, the injection of the intestinal contents of salmon pre-smolts into brown trout was investigated. In all cases the injection proved fatal to the brown trout. Post mortem bacteriological examination of these fish yielded a complex microflora in the kidney. For these reasons, no injection of intestinal material was attempted in the experiments reported here.

A total of 40 paired samples (20 blood samples and 20 combined mucus, fins and gills suspensions) were collected from group D salmon. Forty individually held brown trout were injected intraperitoneally (i.p.) with either $0.1 \mathrm{ml}$ of combined mucus, fins and gills suspension $(n=20)$ or $0.1 \mathrm{ml}$ blood $(n=20)$. Each injected trout was held at $18^{\circ} \mathrm{C}$ for $14 \mathrm{~d}$. The kidneys of all stressed salmon mortalities (group C) and injected brown trout mortalities were examined by standard bacteriological methods on TSA and BHIA (Drinan 1985).

\section{RESULTS}

\section{Comparison of ELISA, bacteriology and stress test}

The results of the stress test administered to the 30 salmon in group $\mathrm{A}$ are shown in Table 1 . One fish failed to survive the initial stress and was not examined further. The kidneys of the 7 fish that died during the test were examined bacteriologically. Aeromonas salmonicida was isolated from 5 of these fish. These fish also gave positive ELISA results for kidney, intestinal contents and mucus. Of the 2 fish from which A. salmonicida could not be isolated from kidney material, one gave a positive ELISA reaction for kidney, intestinal content and mucus while the other was positive for intestinal contents only. The salmon which survived the stress test were sacrificed after $14 \mathrm{~d}$. A. salmonicida was cultured from the kidneys of 2 of these fish and these fish also gave a positive ELISA reaction in samples of their kidney, intestinal contents and mucus. Of the remaining 20 fish from which A. salmonicida was not isolated, 3 gave positive ELISA reactions in intestine samples only and 1 was positive in mucus samples only. Thus, following the stress test, A. salmonicida was detected in $7 / 29$ salmon by the application of culture techniques to kidney material and in $13 / 29$ salmon by the application of ELISA techniques to kidney, intestinal contents or mucus samples.

Bacteriological examination of the mucus, intestinal contents and kidney of the 30 unstressed fish in group $B$ yielded no Aeromonas salmonicida colonies on the 2 media used. Examination of the same samples with ELISA yielded 15 positive intestinal samples and no

Table 1. Examination of individual pre-smolt Atlantic salmon Salmo salar for Aeromonas salmonicida after stress testing. Results given as A. salmonicida detected ( + ) or not detected (-). Fish that survived to Day 14 were sacrificed and examined. In the bacteriological tests, no difference was found between TSA and BHIA

\begin{tabular}{|ccccc|}
\hline $\begin{array}{c}\text { Days } \\
\text { to death }\end{array}$ & Kidney & $\begin{array}{c}\text { ELISA } \\
\text { Intestine }\end{array}$ & Mucus & $\begin{array}{c}\text { Bacteriology } \\
\text { Kidney }\end{array}$ \\
\hline 4 & - & + & - & - \\
4 & + & + & + & - \\
4 & + & + & + & + \\
5 & + & + & + & + \\
7 & + & + & + & + \\
8 & + & + & + & + \\
9 & + & + & + & + \\
14 & + & + & + & + \\
14 & + & + & + & + \\
14 & - & + & - & - \\
14 & - & + & - & - \\
14 & - & + & - & - \\
14 & - & - & + & \\
\hline
\end{tabular}


Table 2. Examination of pre-smolt Atlantic salmon Salmo salar for Aeromonas salmonicida prior to stress testing. Results given as no. of fish positive $(n=30)$. In the bacteriological tests, no difference was found between TSA and BHIA

\begin{tabular}{|cccccc|}
\hline \multicolumn{3}{c}{ ELISA } & \multicolumn{3}{c|}{ Bacteriology } \\
Kidney & Intestine & Mucus & Kidney & Intestine & Mucus \\
\hline $0 / 30$ & $15 / 30$ & $0 / 30$ & $0 / 30$ & $0 / 30$ & $0 / 30$ \\
\hline
\end{tabular}

positives from either the kidney or mucus (Table 2). The number of infections detected in unstressed salmon in group B by ELISA (15/30) was significantly different from the number detected by bacteriological examination of stressed salmon in group A (7/29) $\left(\chi^{2}=4.22,0.05>n>0.025\right)$ When the stressed smolts in group $\mathrm{A}$ were examined by ELISA, the number of infected fish detected (13/29) was not significantly different from that detected using the same method on the unstressed fish in group B $(15 / 30)\left(\chi^{2}=0.158\right.$ $\mathrm{p}>0.5)$.

\section{Comparison of brown trout enrichment, bacteriology and stress test}

In a second series of experiments, brown trout enrichment was used to detect the presence of Aeromonas salmonicida in combined mucus, fins and gills samples from pre-smolt Atlantic salmon. Forty salmon from the same holding tank were divided into 2 groups. Twenty salmon (group C) were submitted to the stress test, and brown trout enrichment was used to detect $A$. salmonicida in a combined fins, gills and mucus sample taken from the other group of 20 salmon (group D). As a control, blood samples were also taken from the salmon in group D and examined by brown trout enrichment. This experiment was repeated and the results of both experiments using this protocol are shown in Table 3. In both experiments attempts to isolate $A$. salmonicida from either the combined mucus, fins and gills or the

Table 3. Detection of Aeromonas salmonicida in asymptomatically infected pre-smolt Atlantic salmon Salmo salar by stress test (modified method of Scallan \& Smith 1984) and brown trout enrichment (i.p. injection of $0.1 \mathrm{ml}$ combined mucus, fins and gills or $0.1 \mathrm{ml}$ blood per brown trout). Results of bacteriological examination of kidneys of brown trout used for each detection method are given $(n=20)$

\begin{tabular}{|cccc|} 
& Stress test & \multicolumn{2}{c|}{ Brown trout enrichment } \\
& & Combined & Blood \\
\hline Expt 1 & $10 / 20$ & $7 / 20$ & $3 / 20$ \\
Expt 2 & $16 / 20$ & $14 / 20$ & $2 / 20$ \\
\hline
\end{tabular}

blood from the unstressed smolts in group D were unsuccessful. Combining the results of the 2 experiments there was no significant difference $\left(\chi^{2}=1.28, p>0.2\right)$ between the frequency with which asymptomatic infections were detected by bacteriological examination of the kidneys of stressed salmon (group C) and the frequency with which $A$. salmonicida was detected in the combined fins, gills and mucus samples of unstressed salmon by brown trout enrichment (group D). There was, however, a significant difference between the number of asymptomatically infected salmon detected by the stress test and those in which A. salmonicida was detected in blood samples by brown trout enrichment $\left(\chi^{2}=23.2, p<0.001\right)$. In both experiments, the numbers of salmon in which $A$. salmonicida was detcctcd in the combined fins, gills and nucus using brown trout enrichment was higher than those in which it was detected in the blood. This difference was significant $\left(\chi^{2}=14.6, \mathrm{p}<0.001\right)$. It is therefore unlikely that the positive isolations following the injection of combined fins, gills and mucus material into brown trout can be accounted for by contamination of these samples with blood.

\section{DISCUSSION}

The first set of experiments was designed to compare the efficiency of the detection of asymptomatic infections achieved using the standard stress test with either bacteriological examination or ELISA examination of samples taken from unstressed fish. In these experiments no asymptomatically infected pre-smolt salmon were detected by standard bacteriological examination of kidney, mucus or intestinal samples. Rose et al. (1989) also failed to culture Aeromonas salmonicida from the kidneys and rectum of asymptomatically infected fish. Bullock \& Stuckey (1975) used bacteriological examination of kidney samples to compare the efficiency of the detection of asymptomatic infections in stressed fish injected with triamcinolone acetonide and unstressed fish. In 94 trout examined they detected asymptomatic infections in $33 \%$ of the stressed and $0 \%$ of the unstressed fish. Scallan (1983), using prednisolone acetate (McCarthy 1977), examined 2 groups of 132 salmon pre-smolts from the same population. In the group submitted to the stress test, 94 $(72 \%)$ infected fish were detected bacteriologically, while in the unstressed group bacteriological examination of the kidney detected $5(3.8 \%)$ infected fish and intestinal culture detected $2(1.5 \%)$. These results demonstrate that the stress test is significantly more efficient at detecting asymptomatic infections than standard bacteriological examination of the kidneys of unstressed fish. Daly \& Stevenson (1985) have presented 
data showing that culturing a variety of organs from unstressed salmon will approximately double the number of infections that can be detected bacteriologically. This improvement in bacteriological detection frequency would still result in detection frequencies significantly lower than those obtained by the stress test. It is possible that bacteriological examination may only detect fish with sub-clinical $A$. salmonicida infections rather than those with true asymptomatic infections. If this is true, then the observations of Daly \& Stevenson (1985) concerning the presence of $A$. salmonicida in a variety of internal organs may not be relevant to the question about the location of the pathogen in fish with true asymptomatic infections. In order to partially clarify the problem of the experimental definition of asymptomatic infections, Smith (1991) suggested that those covert infections detected by the stress test should be termed stress-inducible furunculosis (SIF). The relationship between SIF and asymptomatic infection detected by other methods should be considered unknown.

The failure in this work to detect Aeromonas salmonicida antigen in the kidney of unstressed fish is unlikely, for a variety of reasons, to be due to a failure of the method. The commercial ELISA kit was specifically developed to examine kidney samples, and in our hands it was clearly capable of detecting antigen in the kidneys of stressed fish. Rose et al. (1989), using the same ELISA kit, were able to detect significant antigen in the kidneys and intestines of unstressed fish. The significance of the detection, in this work, of antigen in the intestine of unstressed fish warrants discussion. It is possible that its presence in the intestine of the fish studied was a consequence of contamination of the commercial feed pellets used in the hatchery. This possibility has not been examined by other authors investigating the location of the pathogen in asymptomatically infected fish (Klontz 1968, McDermott \& Berst 1968, Daly \& Stevenson 1985, Rose et al. 1989). Two factors, however, suggest that feed contamination was not a likely explanation for the presence of the antigen detected in the intestinal samples. First, bacteriological examination of 17 samples of commercial feed pellets available in Ireland, not unfortunately including the pellets fed to the smolts prior to these experiments, has failed to detect any culturable A. salmonicida (unpubl. results). Second, in the experiments reported here, the salmon smolts had been starved for $2 \mathrm{~d}$ prior to their leaving the hatchery, and for $3 \mathrm{~d}$ in the laboratory prior to examination. This period of starvation is considered to have been sufficient to have significantly reduced any antigen that might have been present in the feed. This is particularly true considering that the sensitivity of the ELISA was $10^{4}$ cell equivalents of antigen per $\mathrm{ml}$.
Rose et al. (1989) compared ELISA and the stress test in the detection of asymptomatic infections using the same commercial ELISA kit as was used in this work. They found that antigen could be detected by ELISA examination of the kidneys (27/57) and the intestine $(9 / 27)$ of unstressed Atlantic salmon. In these experiments the stress test detected 14/53 infected fish. It is not clear why this result is in complete disagreement with the results reported here, where examination of the kidneys of unstressed salmon failed to detect any Aeromonas salmonicida antigen. Rose et al. (1989) reported an average of $1.2 \times 10^{4} \pm 1.0 \times 10^{3}$ bacteria in the kidneys of their asymptomatically infected salmon. Drinan (1985) reported a similar A. salmonicida concentration in the kidneys of salmon $3 \mathrm{~d}$ after they had been injected i.m. with $10 \times \mathrm{LD}_{50}$ of the pathogen. These fish died 3 d later. The high pathogen concentration reported by Rose et al. (1989) in the kidneys of the fish they examined raises the possibility that these fish had received an unintentional stress prior to their examination, and that, at the time of sampling, they were in the early stages of a clinical infection. McCarthy (1977) has shown that the kidney is the first organ from which $A$. salmonicida can be cultured following the administration of the standard stressors to salmonids with asymptomatic infections.

Cipriano et al. (1992) have suggested that Aeromonas salmonicida can be cultured, using Coomassie Brilliant Blue Agar (CBBA), from the mucus of trout taken from a population with a previous history of furunculosis. In this work we failed to $\operatorname{detect} A$. salmonicida in the mucus of unstressed salmon either by bacteriological examination or ELISA. The failure to culture $A$. salmonicida from the mucus of unstressed salmon (groups B and D) in this work may, on the other hand, be a function of the media used. CBBA is not a selective medium for A-layer positive A. salmonicida but has been reported to facilitate its recognition on culture plates (Cipriano \& Bertolini 1988, Teska \& Cipriano 1993). However, the use of CBBA for the isolation of $A$. salmonicida has not been found to give any selective advantage over TSA in this laboratory (Hiney 1994). The ELISA technique was capable of detecting $A$. salmonicida in the mucus of pre-smolt salmon examined following the stress test (group A) but no positives were detected in samples from unstressed salmon (group B). It is possible that this failure is a function of the low pathogen numbers in the mucus. Cipriano et al. (1992) detected approximately $10^{3} \mathrm{cfu} \mathrm{g}^{-1}$ in their mucus samples while the limit of detection of the commercial ELISA kit used in this work was $1 \times 10^{4}$ cells.

In order to investigate the possible presence of low numbers of Aeromonas salmonicida in the mucus of unstressed pre-smolt salmon, the brown trout enrich- 
ment technique was developed. The rationale underlying this technique is that the $\mathrm{LD}_{50}$ of $A$. salmonicida for brown trout held in our laboratory is regularly under 1 cfu fish ${ }^{-1}$ (Drinan 1985). Thus, brown trout represent a highly sensitive, semi-selective enrichment medium for the isolation of $A$. salmonicida. The results of the trout enrichment experiments clearly illustrate that $A$. salmonicida can be detected in the combined mucus, fin and gill samples of unstressed salmon. The frequency of its detection was not significantly different from the frequency at which the stress test detected infections in a paired group of salmon.

The results of this work suggest that the frequency with which Aeromonas salmonicida can, using certain techniques, be deterted in samples from unstressed salmon pre-smolts is similar to the frequency with which asymptomatic infections can be detected by the stress test. In unstressed pre-smolts the successful detection methods were examination of samples of the intestines using ELISA techniques or examination of the gills, fins and mucus using brown trout enrichment. These data are in general agreement with the work of Klontz (1968) and Markwardt \& Klontz (1989a) who have suggested that the intestine is the major location of the pathogen in asymptomatically infected fish and Cipriano et al. (1992) who suggested that the mucus was a second important location. The hypothesis that the primary location of $A$. salmonicida is on the external surfaces of fish is supported by the work of Smith \& Davey (1993). They reported the elimination of asymptomatic infections in pre-smolt salmon by competitive exclusion with a bath-applied fluorescent pseudomonad. In this treatment, the pseudomonad was not detected in the internal organs of the smalts and it was concluded that the competition occurred on the external surfaces of the smolts

The reported methods for the control or elimination of asymptomatic infections all involve the generation of high serum levels of antibiotics (McCarthy 1977, Roberts 1980, Scallan \& Smith 1985, Markwardt \& Klontz 1989b, O'Grady \& Smith 1992). If Aeromonas salmonicida is located on the external surfaces of fish with asymptomatic infections, high serum levels of antibiotics may not prove effective at eliminating these infections. The elimination of such infections may be achieved by the administration of chemotherapeutants that themselves remain external to the fish. The range of agents that should be tested for the ability to eliminate asymptomatic infections might be extended to include those in the aminoglycoside group of antibiotics, such as streptomycin, neomycin or tobramycin. These antibiotics are poorly absorbed by the intestinal tract and are primarily used in veterinary medicine in the treatment of enteric and skin infections (Prescott \& Baggott 1988).

\section{LITERATURE CITED}

Bullock, G. L., Stuckey, H. M. (1975). Aeromonas salmonicida detection of asymptomatically infected trout. Prog. Fish. Cult. $37: 237-239$

Cipriano, R. C., Bertolini, J. B. (1988). Selection for virulence in the fish pathogen Aeromonas salmonicida using Coomassie Brilliant Blue agar. J. Wildl. Dis. 24: 672-678

Cipriano, R. C., Ford, L. A., Teska, J. D., Hale, E. H. (1992). Detection of Aeromonas salmonicida in the mucus of salmonid fishes. J aquat. Anim. Health 4: 114-118

Daly, J. G., Stevenson, R. M. W. (1985). Importance of culturing several organs to detect Aeromonas salmonicida in salmonid fish. Trans. Am. Fish. Soc. 114: 909-910

Drinan, E. M. (1985). Studies on the pathogenesis of furunculosis in salmonids. Ph.D. thesis, National University of Ireland, Dublin

Hastings, T S. (1988). Furunculosis vaccines. In: Ellis, A. E. (ed.) Fish vaccination. Academic Press: London. n 9.3-111

Hiney, M. P. (1994). Techniques in the study of epizootiology of the fish disease furunculosis. Ph.D. thesis, National University of Ireland, Dublin

Horne, J. H. (1928). Furunculosis in trout and the importance of carriers in the spread of the disease. J. Hyg. 28: 67-78

Klontz, G. W. (1968). Oral immunisation of coho salmon against furunculosis. In: Progress in sport fishery research. Bur. Sport Fish. Wildl. Resource Publ. 39, p. 81-82

Mackie, T J., Menzies, W. J. (1938). Investigations in Great Britain of furunculosis of salmonidae. J. comp. Pathol. Therap. 51: 225-234

Markwardt, N. M., Klontz, G. W. (1989a). Evaluation of four methods to establish asymptomatic carriers of Aeromonas salmonicida in juvenile spring chinook salmon, Oncorhynchus tshawytscha (Walbaum). J. Fish Dis. 12: 311-315

Markwardt, N. M., Klontz, G. W. (1989b). A method to eliminate the asymptomatic carrier state of Aeromonas salmonicida in salmonids. J. Fish Dis. 12: 317-322

McCarthy, D. H. (1977). Some ecological aspects of the bacterial fish pathogen, Aeromonas salmonicida. Aquatic Microbiol., SAB Symposium, 6: 199-324

McDermott, L. A., Berst, A. H. (1968). Experimental plantings of brook trout (Salvelinus fontinalis) from furunculosis infected stock. J. Fish. Res. Bd Can. 25: 2365-2370

Mettam, A. E. (1914). Report on the outbreak of furunculosis in the river Liffey in 1913. Scientific Investigations of the Fisheries Branch, Department of Agriculture for Ireland, Dublin

O'Grady, P., Smith, P. (1992). Use of Flumisol bath treatments to eliminate stress inducible furunculosis in salmon smolts. Bull. Eur. Ass. Fish Pathol. 12: 201-203

Plehn, M. (1911). Die Furunkulose der Salmoniden. Zbl. Bakteriol. ParasitKde 60: 609-624

Prescott, J. F., Baggott, J. D. (1988). Antimicrobial therapy in veterinary medicine. Blackwell Scientific Publications, Oxford

Roberts, S. D. (1980). A method of reducing the carrier state of Aeromonas salmonicida in juvenile pacific salmon. Ph.D. thesis, University of Idaho, Moscow

Rose, A. S., Ellis, A. E., Adams, A. (1989). An assessment of routine Aeromonas salmonicida carrier detection by ELISA. Bull. Eur. Ass. Fish Pathol. 9: 65-67

Scallan, A. (1983). Investigations into asymptomatic carriers of furunculosis. Ph.D thesis, National University of Ireland, Dublin

Scallan, A., Smith, P. R. (1984). Investigations into seasonal variation of latent furunculosis. In: Acuigrup (ed.) Fish diseases - enfermedades de los peces. Proceedings of the 
fourth session of EIFAC/COPRAQ on fish disease, Cadiz. Kaher II, Madrid, p. 53-58

Scallan, A., Smith, P. R. (1985). Control of asymptomatic carriage of Aeromonas salmonicida in Atlantic salmon smolts with flumequine. In: Ellis, A. E. (ed.) Fish and shellfish pathology. Academic Press, London, p. 119-127

Smith, P. R. (1991). Stress test picks up furunculosis carriers. Fish Farmer 14: 18

Responsible Subject Editor: T. Evelyn, Nanaimo, B.C., Canada
Smith, P. (1992). Antibiotics and the alternatives. In: De Pauw, N., Joyce, J. (eds.) Aquaculture and the environment. European Aquaculture Society Spec. Publ. No. 16, Gent, Belgium, p. 223-234

Smith, P., Davey, S. (1993). Evidence for the competitive exclusion of Aeromonas salmonicida from fish with stressinducible furunculosis by a fluorescent pseudomonad. J. Fish Dis. 16: 521-524

Manuscript first received: March 12, 1993 Revised version accepted: May 16, 1994 